This item was submitted to Loughborough's Research Repository by the author.

Items in Figshare are protected by copyright, with all rights reserved, unless otherwise indicated.

\title{
Finite element modelling of a pneumatic tyre interacting with rigid road and deformable terrain
}

PLEASE CITE THE PUBLISHED VERSION

http://dx.doi.org/10.1504/IJVP.2017.083359

\section{PUBLISHER}

(C) Inderscience

\section{VERSION}

AM (Accepted Manuscript)

\section{PUBLISHER STATEMENT}

This work is made available according to the conditions of the Creative Commons Attribution-NonCommercialNoDerivatives 4.0 International (CC BY-NC-ND 4.0) licence. Full details of this licence are available at: https://creativecommons.org/licenses/by-nc-nd/4.0/

\section{LICENCE}

CC BY-NC-ND 4.0

\section{REPOSITORY RECORD}

Bekakos, Chrysostomos, George Papazafeiropoulos, Daniel O'Boy, and Jan Prins. 2016. "Finite Element Modelling of a Pneumatic Tyre Interacting with Rigid Road and Deformable Terrain". figshare. https://hdl.handle.net/2134/22549. 


\title{
Finite element modelling of a pneumatic tyre interacting with rigid road and deformable terrain
}

\author{
Chrysostomos-Alexandros Bekakos* \\ Department of Aeronautical and Automotive Engineering, \\ Loughborough University, \\ Epinal Way, LE11 3TU, \\ Loughborough, Leicestershire, UK \\ Email: c.bekakos@lboro.ac.uk
}

\section{George Papazafeiropoulos*}

Department of Structural Engineering,

School of Civil Engineering,

National Technical University of Athens,

9, Iroon Polytechniou St.,

15780 Zografou, Athens, Greece

Email: gpapazafeiropoulos@yahoo.gr

${ }^{\star}$ Corresponding authors

\section{Dan J. O'Boy}

Department of Aeronautical and Automotive Engineering, Loughborough University,

Epinal Way, LE11 3TU, Loughborough, Leicestershire, UK

Email: d.j.oboy@lboro.ac.uk

\section{Jan Prins}

Jaguar Land Rover,

Banbury Road, Gaydon,

Warwickshire CV35 0RR, UK

Email:jprins@jaguarlandrover.com

\begin{abstract}
In this study, the dynamic interaction between a pneumatic P235/75R17 tyre and a rigid and/or deformable rolling surface is analysed using the finite element method. After a footprint analysis of the tyre, two models were developed: (a) tyre rolling on rigid road with bumps and (b) tyre rolling on the surface of a soft soil layer, appropriate for off-road vehicle handling. In the first model, a steady-state transport analysis is performed to obtain the free rolling conditions of the tyre, which are then used to simulate the impact of the tyre on a rigid bump, typical of a road cleat or speedbump. In the second model, the transient rolling response of the tyre on a soft cohesive soil layer was simulated under towed and driven conditions. Along with a concise literature review and detailed description of the numerical models considered, various response quantities along with deformed geometries are provided throughout the text. It is finally shown that the dynamic response
\end{abstract}

AQ1: Please reduce abstract of no more than 150 words. 
of the rolling tyre and its interaction with the deformable soil is inherently complex and depends on many parameters, whereas it is proven that the overall performance of the off-road tyres depends on significantly different parameters from that of the on-road tyres.

Keywords: tyre; finite element method; steady-state transport; tyre-bump impact; tyre-soil interaction; terramechanics.

Reference to this paper should be made as follows: Bekakos, C-A., Papazafeiropoulos, G., O'Boy, D.J. and Prins, J. (xxxx) 'Finite element modelling of a pneumatic tyre interacting with rigid road and deformable terrain', Int. J. Vehicle Performance, Vol. x, No. x, pp.xxx-xxx.

Biographical notes: Chrysostomos-Alexandros Bekakos is a $\mathrm{PhD}$ student (2013-) at the Aeronautical and Automotive Engineering Department, Loughborough University, supervised by Dr. Dan O'Boy. He has graduated from the School of Mechanical Engineering of the National Technical University of Athens (2011).

George Papazafeiropoulos works as an Infrastructure Engineer at the Hellenic Air Force/Air Defence Fund with the rank of Captain. He has graduated from the Hellenic Air Force Academy (HAFA) (2007), as a chief student in his specialty. He is also a Professional Civil Engineer of the National Technical University of Athens (NTUA) (2011). He holds an MSc from Technical University of Crete on "Science and Technology of Materials and Structures" (2010) and is currently a Doctoral Candidate at the Institute of Structural Analysis \& Seismic Research (ISASR), Department of Structural Engineering, School of Civil Engineering, NTUA (2011-).

Dan J. O'Boy is a Lecturer in Structural Dynamics in the Department of Aeronautical and Automotive Engineering and Program Director for Automotive Engineering in Loughborough University. He holds a ME in Mechanical Engineering from University of Bristol and a PhD in Engineering from University of Cambridge.

Jan Prins is a Technical Specialist for Tyre CAE \& Modelling at Jaguar Land Rover (JLR). He has graduated from Delft University of Technology in the Netherlands. Furthermore, he is a STEM (Science Technology Engineering and Mathematics) ambassador and actively supports the Land Rover $4 \times 4$ in Schools Challenge. He has also been an IMechE mentor since becoming a Chartered Engineer.

This paper is a revised and expanded version of a paper entitled [title] presented at [name, location and date of conference].

AQ2: If a previous version of your paper has originally been presented at a conference please complete the statement to this effect or delete if not applicable.

\section{Introduction}

Tyres have a major role on the overall dynamic interaction between a vehicle and the ground surface, being either a stiff pavement or soft soil. There is an increasing demand to determine the bearing capacity of the various types of rolling surfaces, and thus to select the most suitable tyre in terms of vehicle's energy efficiency and tread wear retardation, which will enable a vehicle to have the optimum traction performance. To 
achieve this match early in the vehicle design phase, it is necessary to develop accurate numerical models of the tyre and the road (either stiff or deformable) as well as the static or dynamic interaction between them, in order to investigate in which way the constitutive properties of the road affect the tyre performance. The degree in which the numerical simulations capture the real conditions is closely related to the technically correct and economical tyre design. Moreover, the complex nature of the phenomena involved in the tyre-road interaction usually cannot be sufficiently described by simpler analytical and/or empirical solutions, and in many cases resorting to numerical simulations is the only effective alternative. As a result of the above, the open issue of interaction between tyres and roads has drawn much attention from various researchers, aiming at providing a thorough explanation of this complicated phenomenon.

The importance of validating the dynamic properties of a tyre model prior to its implementation into a transient dynamic model is necessary in terms of ensuring that the tyre model represents a realistic tyre and can be implemented on a range of scales. The dynamic properties of a tyre can be evaluated by considering its natural frequencies, mode shapes and modal loss factors. The dynamic excitation of a rolling tyre comes mainly from three main sources:

- road surface irregularities, potholes, bumps

- dynamic loads originating from various non-uniformities of the tyre, such as slight imbalances or asymmetric tread pattern designs

- vehicle control inputs such as steering and braking.

Consequently, the dynamic response of a tyre, which is present in its most common applications, is of high importance. Wheeler et al. (2005) performed FEM analyses to extract the various eigenmodes of a P235/75R 17 tyre, which were further categorised in a way that describes best the meaning and value of individual modes. The vibration modes of radial tyres on a fixed spindle are presented and the effect of the tyre components and their contribution in the mode shapes is investigated. Given that in most cases the material properties and/or the geometry of a tyre are not explicitly specified, an optimisation analysis was set up and conducted by Bekakos et al. (2016a) in order to obtain a number of these properties, such as belt thickness, with the constraint that the eigenfrequencies are equal to the corresponding eigenfrequencies given by Wheeler et al. (2005). Modal analysis has been applied for tyres in many ways; for example, Bolarinwa and Olatunbosun (2015) obtained the footprint of a tyre under purely vertical load, and performed a frequency analysis maintaining the contact conditions by applying an equivalent distributed vertical load, whereas the centre of the wheel was set free in all degrees of freedom. It was found that the boundary conditions on the tyre model can have large impact on its eigenmode response.

In addition, it is common knowledge that the contact conditions between the tyre and the road or terrain have a significant impact on its dynamic response. One of the major factors which control the contact conditions is the friction at the tyre-terrain interface. In many cases, it is desired that the effects of friction be eliminated, in order to focus on the effect of the remaining parameters affecting the tyre-terrain interaction. The state at which there is no torque applied at the wheel centre, i.e., the free rolling condition, is necessary to be found in such cases and is usually calculated by conducting a steady-state transport (SST) analysis. Such types of analysis have been presented by Ghoreishy 
(2006) for a 175/70R14 steel-belted radial tyre under footprint load, where close agreement is observed with experimental data.

It is noted that the SST analysis cannot incorporate any transient effects, such as tyres rolling over bumps, or other irregularities. After calculating the free rolling conditions for the pneumatic tyre of interest, the transient response can be modelled, where the tyre-terrain interaction mechanism can be explicitly observed. Kamoulakos and Kao (1998) studied the transient dynamic response of a rolling tyre impacting a road imperfection (bump) represented by a cleat on a rotating drum using PAM-SHOCK and good correlation between the results and experimental data was found. Cho et al. (2005) studied the transient dynamic analysis of a 3D treaded tyre subject to impact loading originating from a rigid cleat. The numerical results were verified by experimental data, and a parametric analysis was conducted. It was shown that the horizontal and vertical forces at the tyre axis were highly affected by the rolling speed, while the inflation pressure has a less important effect. Wei and Olatunbosun (2014) modelled the transient dynamic response of a pneumatic tyre rolling over obstacles with different height and studied the effects of travelling velocity and height of the rectangular cleat. They concluded that the resonant amplitude of the reaction forces was highly influenced by both speed and height of the obstacle.

Regarding the rolling surface, the assumption that it is rigid is not realistic in the cases of flexible pavements and off-road conditions. In the latter cases, the flexibility of the road or soil, respectively, which gives rise to the tyre-terrain interaction, has to be taken into account. Kölsch (2000) considered a nonlinear soft soil material using the modified drucker-prager (DP) cap model where a vehicle was rolling over soft road bumps. It was found that the dynamic interaction between the deformable terrain and the wheels was intense, in particular for the rear wheels, which roll over an already deformed rut path created by the front wheels. Further research on pneumatic tyres rolling over deformable terrains was conducted by Fervers (2004) for two types of soils described by the DP cap plasticity model. The first soil type was set to have high cohesion and zero friction angle (cohesive) representative of a wet loose loam and the second soil type was set to have low cohesion and high value of friction angle (frictional), representative of a dry sand. Lee (2011) used the aforementioned constitutive model to represent snow and studied the tyre forces which developed under various rolling conditions. It was observed that the sinkage (vertical displacement) of the tyre into the soil depends highly on the longitudinal and lateral slip. Furthermore, the deflection of the tyre was negligible compared to the deformation of the snow, a fact which justifies the use of a rigid wheel model. Bekakos et al. (2016b) studied the static and dynamic interaction of two deformable tyres with different aspect ratios with rigid and soft soil. They found that by increasing the aspect ratio of the tyre, the sinkage of the wheel into the soft soil is decreased, and that the friction coefficient affects significantly the contact area on rigid terrains for small vertical loads, whereas for large vertical loads the rebar orientation has an important influence on the deflection of the tyre.

Shoop (2001) created a 3D model for the tyre-terrain interaction, in which two material models were taken into account, namely a modified DP cap plasticity model and a critical state, crushable foam model. Both models were considered adequate for the simulation of fresh snow, whereas only the cap model was used for modelling the sandy soil. Both rigid and deformable tyres were considered; it is again noted that a deformable tyre with a relatively high-inflation pressure rolling on a relatively soft terrain, can be assumed to behave as rigid. Chiroux et al. (2005) modelled the interaction of a rigid 
wheel with a deformable terrain using again the above-mentioned soil constitutive model and observed that the soil tends to rebound after the passage of the wheel. Despite the rebound, the numerical results were found in close agreement with experimental data. Hambleton and Drescher $(2008,2009)$ studied the indentation and rolling response of a rigid wheel on deformable soil, respectively. The soil is modelled as an elastic-perfectly plastic material and the effect of wheel aspect ratio on the sinkage and required horizontal force is investigated. On the basis of this research, Bekakos et al. (2015) investigated the behaviour of a towed treaded rigid wheel rolling on cohesive and frictional soils. A novel approach was presented for the matching of mohr-coulomb (MC) and DP models in three dimensions, which was further confirmed by the numerical results. The results were found to be in close agreement with the results published in the literature.

In this study, the transient dynamic response of a pneumatic tyre rolling over rigid and deformable terrains is examined. In the case of rigid terrains, SST analyses are conducted in order to calculate the free rolling conditions of the tyre. Following that the combinations of linear and angular velocities corresponding to the free rolling condition are used to study the dynamic behaviour of the tyre rolling over rigid surfaces with bumps. Apart from these, a parametric study of the dynamic interaction between a deformable tyre and soft cohesive soil, described by the linear DP constitutive model is examined for both cases of a towed and driven wheel.

\section{Numerical modelling}

\subsection{General}

The rolling response of a pneumatic tyre interacting with rigid or deformable terrain is modelled numerically using the finite element code ABAQUS 6.13. A 2D half-axisymmetric tyre model is firstly developed, from which the final configuration of the inflated tyre is acquired. Using the symmetric model generation (SMG) and the symmetric results transfer (SRT) capabilities of ABAQUS, this 2D half-axisymmetric model is extended to a half 3D tyre model, where the footprint of the tyre is obtained either by imposing a vertical load at its centre against a fixed analytical rigid surface (in the case of the tyre rolling on a deformable soil), or imposing a vertical load at a rigid analytical surface against the tyre, with its centre fixed (in the cases of SST analysis of the tyre and of the latter rolling on a rigid surface with bump). Following that, SMG and SRT are reused to extend the half 3D tyre model into a full 3D tyre configuration. From this point, modelling proceeds in two directions which will be referred from now on as

- $\quad$ tyre-rigid terrain interaction model

- $\quad$ tyre-deformable terrain interaction model.

In the first part, the analysis begins from the results of the 3D model described above, and using the SST utility of ABAQUS/Standard, the steady-state response of the tyre rolling on a rigid analytical surface is obtained. Details about the capabilities and characteristics of this type of analysis are presented in a subsequent section. The main result of the SST analysis is the free rolling condition of the tyre. The results related to this condition are imported into another model which contains a rigid analytical surface with a bump. In this last model a transient dynamic explicit analysis (with ABAQUS/explicit) is 
conducted to investigate the dynamic response of the tyre travelling in a free rolling state due to the impact force imposed by the bump.

In the second part of the models considered in this study, the results of the 3D model analysis are imported into another model which contains the soft soil. A transient dynamic explicit analysis (with ABAQUS/explicit) is performed to investigate the dynamic behaviour of the tyre rolling on this soft soil layer under various inflation pressures, linear and/or angular velocities and vertical loads. The modelling procedures involved in the present study are schematically illustrated in Figure 1.

Figure 1 Procedure of development and analysis of the various models used in this study

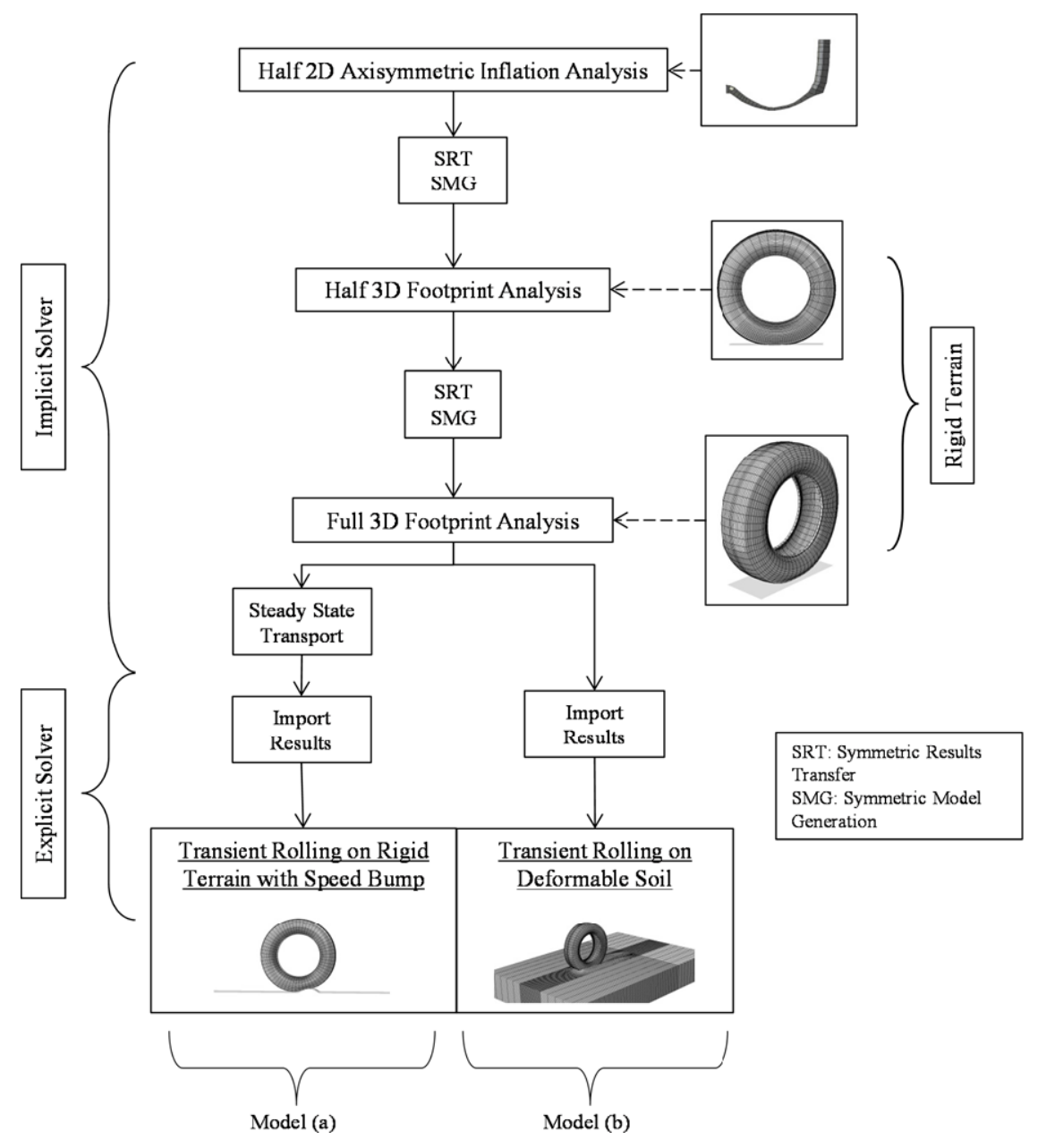

\subsection{Geometry}

\subsubsection{Tyre}

The cross-section of the tyre, P235/75R17, is shown in Figure 2. The tyre is comprised of the belt region, the tread region and the side walls which are being modelled with a hyperelastic material, representative of rubber. The hyperelastic material is simulated by 
the one term polynomial strain energy potential (Mooney-Rivlin model) and with one term Prony series to account for viscoelasticity (Bekakos et al., 2016a). The belt region contains the reinforcement of the two belt layers (illustrated as belt layers 1 and 2 in the figure), and the reinforcement of carcass. The last extends over the belt region, it covers the side walls and surrounds the bead. Both belt layers and the carcass are discretised with surface elements with twist (SMFGAX1). The rim is discretised with two-node, linear links for axisymmetric planar geometries (RAX2), and the belt, bead, sidewall and tread regions are discretised with four-node bilinear, reduced integration elements with hourglass control (CGAX4R). The nodes of the surface elements of the carcass share the same nodes with those of the belt region elements, in order to avoid numerical instabilities which may arise during the analysis. It has to be noted that the rebar cross-sectional areas of the belt and the carcass have been determined in a way that the dynamic properties of the tyre (in terms of its eigenmodes and eigenfrequencies) fit best analogous results in the literature (Wheeler et al., 2005). Their values $\left(3.6482 \times 10^{-7} \mathrm{~m}^{2}\right.$ and $8.0113 \times 10^{-8} \mathrm{~m}^{2}$ for the belts and the carcass, respectively, used in this study) have a large impact on the overall configuration and dynamic response of the tyre under consideration and determine the quality of the results.

Figure 2 Tyre half-cross section geometry

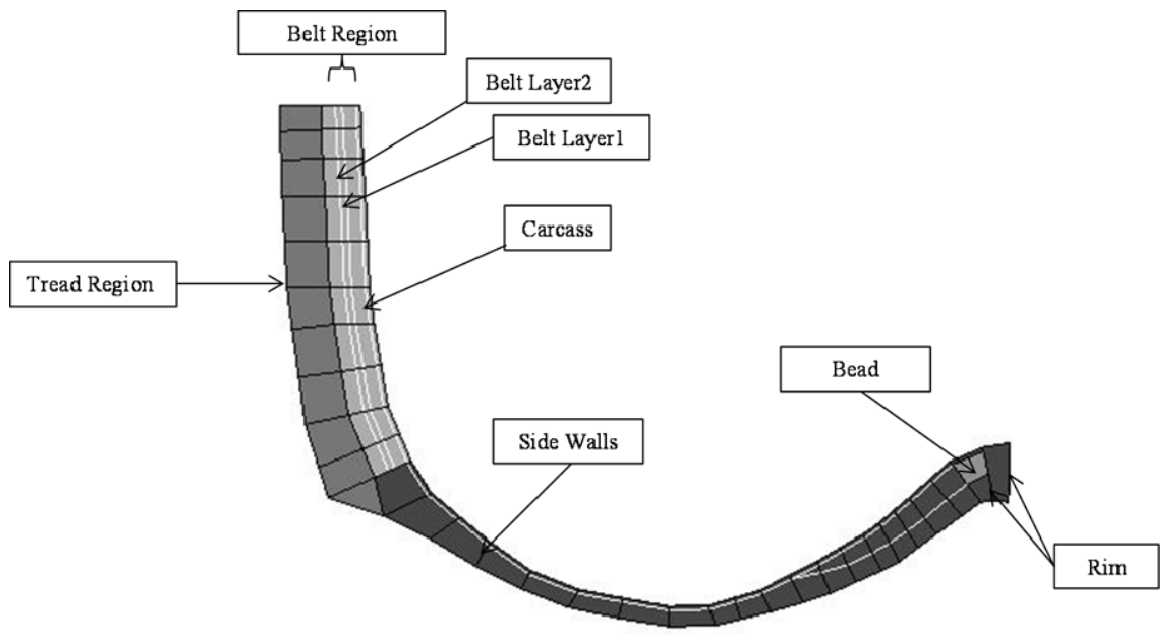

\subsubsection{Terrain}

In model (a), the rigid terrain is represented by a rigid analytical surface of $3.5 \mathrm{~m}$ in length with a bump which is a circular arc with its ends located at 0.5 and $0.7 \mathrm{~m}$, respectively, in front of the initial contact point of the tyre with the terrain. Following conventions according to SAE (2008), the centre of the circular arc is located at $0.6 \mathrm{~m}$ from the latter along $x$-axis and at $0.1 \mathrm{~m}$ below the level of the surface along $y$-axis. It is noted that the position of the analytical surface depends on the deformed configuration of the tyre, which results due to the inflation pressure and the vertical load, since at the beginning of the SST and subsequent transient dynamic explicit analyses the deformed tyre must be in contact with the rolling surface.

In model (b), the soft soil is represented by a solid deformable part, with dimensions $2.9 \mathrm{~m}$ in length, $2 \mathrm{~m}$ in width and $0.4 \mathrm{~m}$ in height. It was discretised with C3D8R 
elements and was partitioned appropriately, so that in the areas closer to the surface and to the rolling region the mesh was finer; the mesh was coarser in the regions far from the tyre.

\subsection{Parameters}

In model (a), two different vertical loads were imposed at the tyre centre (1.2 and $\left.2 \gamma g b d^{2}\right)$ at the inflation pressure of $242 \mathrm{kPa}(\sim 35 \mathrm{psi})$ and the response of the rim after the impact on the bump was studied. For the vertical load of $2 \gamma \mathrm{gbd}^{2}$ three different cases of inflation pressures $(160,200,242 \mathrm{kPa})$ were considered and the effect on the dynamic response of the tyre centre was observed. In all the above cases, the linear velocity of the tyre centre in the $x$ direction is prescribed to be equal to $10 \mathrm{~km} / \mathrm{h}(\sim 2.7778 \mathrm{~m} / \mathrm{s})$. Following this, for the tyre with vertical load of $2 \gamma \mathrm{gbd}^{2}$, inflation pressure of $200 \mathrm{kPa}$ two different linear velocities were considered $(10 \mathrm{~km} / \mathrm{h}$ and $20 \mathrm{~km} / \mathrm{h})$.

In model (b), two different driving conditions were assumed for the pneumatic tyre (towed and driven). For the towed wheel with inflation pressure $242 \mathrm{kPa}$ and vertical load equal to $1.2 \gamma \mathrm{gbd}^{2}$, two different linear velocities were considered $(5$ and $10 \mathrm{~km} / \mathrm{h})$. For a towed wheel with inflation pressure $242 \mathrm{kPa}$ and linear velocity $10 \mathrm{~km} / \mathrm{h}$ two different vertical loads were assumed $\left(1.2\right.$ and $\left.2 \gamma \mathrm{gbd}^{2}\right)$. For a towed wheel with linear velocity $5 \mathrm{~km} / \mathrm{h}$ and vertical load of $1.2 \gamma \mathrm{gbd}^{2}$, two different inflation pressures were used (200 and $242 \mathrm{kPa}$ ). For the driven wheel with $1.2 \gamma \mathrm{gbd}^{2}$ vertical load, the corresponding angular velocity for the free rolling condition for linear velocity equal to $10 \mathrm{~km} / \mathrm{h}(7.46 \mathrm{rad} / \mathrm{s})$ was assumed for four different inflation pressures $(120,160,200,242 \mathrm{kPa})$. For the driven wheel with inflation pressure equal to $242 \mathrm{kPa}$ and angular velocity $7.46 \mathrm{rad} / \mathrm{s}$, two different vertical loads were specified $\left(0.8\right.$ and $\left.1.2 \gamma \mathrm{gbd}^{2}\right)$. For the driven wheel with inflation pressure $242 \mathrm{kPa}$ and vertical load $1.2 \gamma \mathrm{gbd}^{2}$ two different angular velocities were used $(3.73 \mathrm{rad} / \mathrm{s}$ and $7.46 \mathrm{rad} / \mathrm{s})$.

\subsection{Material models}

\subsubsection{Tyre}

The tread, the belt and the sidewall are modelled as hyperelastic materials with viscoelasticity, properties representative of rubber. The hyperelastic material is represented by the one-term polynomial strain energy potential, i.e., the Mooney-Rivlin model:

$$
U=C_{10}\left(\bar{I}_{1}-3\right)+C_{01}\left(\bar{I}_{2}-3\right)+\frac{1}{D_{1}}\left(J^{e l}-1\right)^{2},
$$

where $C_{10}=10^{6} \mathrm{~Pa}, C_{01}=0$ and $D_{1}=5.085 .10^{-8} \mathrm{~Pa}^{-1}$ and $J^{\mathrm{el}}$ is the elastic volume ratio. The material used for the rubber incorporates a time-domain viscoelastic component, defined using one-term Prony series parameters. The parameters used are $\bar{g}_{1}^{P}=0.3, \bar{k}_{1}^{P}=0, \tau_{1}=0.1 \mathrm{~s}$. The belt and the carcass layers, which serve as reinforcement in the main body of the tyre and are discretised with surface finite elements (SMFGAX1) embedded into the latter, are modelled as linear elastic materials with properties $E_{\text {belt }}=1.722 \times 10^{11} \mathrm{~Pa}, E_{\text {carcass }}=9.87 \times 10^{9} \mathrm{~Pa}$ and Poisson ratio equal to 0.3 
for both materials, and densities equal to $5900 \mathrm{~kg} / \mathrm{m}^{3}$ and $1500 \mathrm{~kg} / \mathrm{m}^{3}$, respectively. The density of the rubber material is equal to $1100 \mathrm{~kg} / \mathrm{m}^{3}$.

The $C_{10}$ parameter of the Mooney-Rivlin material described by equation Error! Reference source not found. was determined by Bekakos et al. (2016a) using a suitable optimisation process so that the eigenproperties (eigenfrequencies and eigenmodes) of the tyre fit best analogous results in the literature (Wheeler et al., 2005). It is pointed out that the frequency analyses during the optimisation process were performed for a stationary and unloaded inflated tyre, a condition which implies that the strain rates at all cross sections of the tyre are zero, and therefore the tyre does not experience any specific strain rate (or small band of strain rates) during the calculation of its Mooney-Rivlin parameters. Consequently, the Mooney-Rivlin parameters are valid for zero strain rates. In addition, the instantaneous static elastic solutions were obtained for time-domain viscoelasticity; the analyses were not transient in the sense of the incorporation of time-dependent viscoelastic material behaviour in the static response. Since the expected eigenfrequencies (and stiffness) of the tyre are expected to be lower for a loaded tyre in rolling conditions, compared to a stationary unloaded tyre (see, e.g., Dorfi et al., 2005), the stiffness of the tyre model as defined by Bekakos et al. (2016a) will be larger than the actual stiffness of the tyre under loading and rolling conditions, which is considered in this study. This is a limitation of the tyre modelling technique proposed in the current study. Furthermore, frequency analysis is a linear perturbation procedure about a base state of the model which has resulted from the last general nonlinear loading step. Apart from this, during the static analysis of the tyre for the inflation loading prior to eigenfrequency extraction, the instantaneous elastic solution is obtained for time-domain viscoelasticity and no transient static stress/displacement analysis with time-dependent material response was considered. This implies that, although viscoelasticity was defined for the rubber with one-term Prony series expansion of the shear and bulk relaxation moduli, rate-dependent effects were not taken into account, which are related to the strain rates present in the tyre model. The only use of the viscoelastic parameters is to convert the hyperelastic material constants defining the long-term behaviour into their corresponding instantaneous values, or vice-versa, which are then used for the calculation of the instantaneous static response.

\subsubsection{Soft soil}

The linear DP failure criterion (Drucker and Prager, 1952) was chosen to represent the plastic deformation of the soft soil. The yield surface for DP is:

$$
F_{D P}=\sqrt{\left(\sigma_{1}-\sigma_{2}\right)^{2}+\left(\sigma_{2}-\sigma_{3}\right)^{2}+\left(\sigma_{3}-\sigma_{1}\right)^{2}}+\frac{1}{3}\left(\sigma_{1}+\sigma_{2}+\sigma_{3}\right) \tan \varphi-d_{D P} .
$$

The flow stress ratio in the DP model was set to unity which means that the yield stress in triaxial tension is equal to the yield stress in triaxial compression. Purely cohesive soil was considered for all analyses involving model (b). Non dilatant flow was assumed and the friction angle was set equal to a very small value to avoid numerical convergence problems. The cohesion is equal to $c / \gamma g d=1.25$ and the Young modulus is equal to $E / \gamma \mathrm{gd}=10^{3}$. The deformable part used for model (b) is divided into two regions (Figure 3), i.e., a region containing stiff soil and a region containing soft soil. The region of stiff soil serves for equilibrium purposes so that the final results of the implicit solver 
where the footprint was obtained which can then be used for the initialisation of the transient explicit analysis. The soft soil region participates in the tyre-terrain dynamic interaction during the transient phase.

Figure 3 Reference configuration of the model (b) of this study

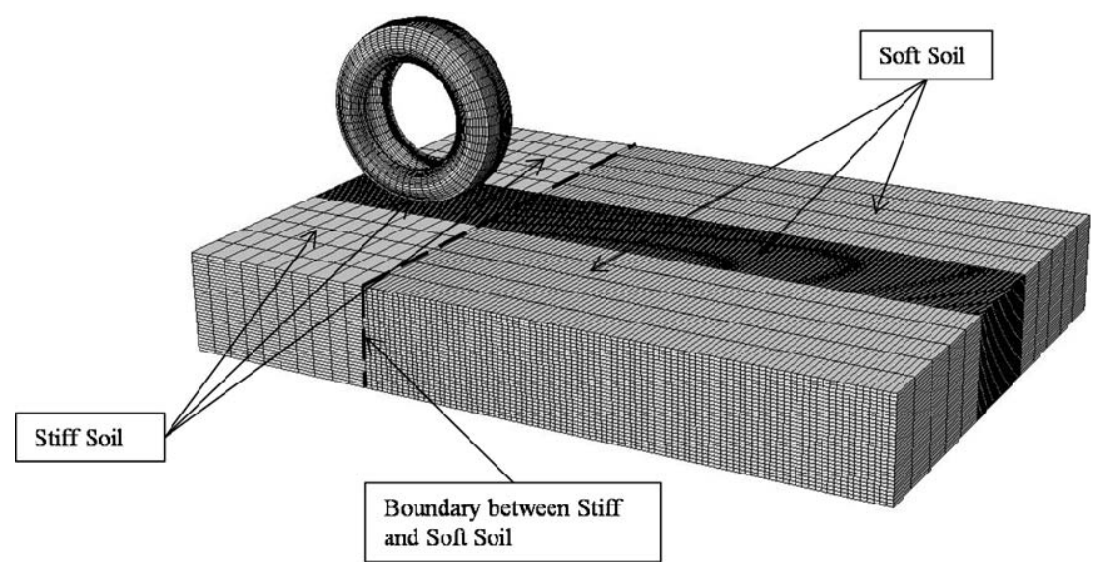

\subsection{Loads and boundary conditions}

\subsubsection{Model (a)}

For all implicit analyses conducted in this model the rim was fixed and the rigid analytical surface was loaded by a concentrated force while being allowed to move along the vertical global $z$-axis. In the SST analysis, the angular velocity is considered to be the imposed loading, whereas the linear velocity is imposed as a boundary condition. The angular velocity ranges from $7.2 \mathrm{rad} / \mathrm{s}$ to $8.2 \mathrm{rad} / \mathrm{s}$. These limits are calculated as follows: the radius of the undeformed tyre is equal to $0.381 \mathrm{~m}$, therefore for travelling speed equal to $2.78 \mathrm{~m} / \mathrm{s}$, the angular velocity is found to be $2.78 / 0.381 \approx 7.3 \mathrm{rad} / \mathrm{s}>7.2 \mathrm{rad} / \mathrm{s}$. For vertical load $5 \mathrm{kN}$ and inflation pressure $242 \mathrm{kPa}$, the radius of the deformed tyre is equal to $0.348 \mathrm{~m}$, which corresponds to angular velocity $2.78 / 0.348 \approx 8 \mathrm{rad} / \mathrm{s}<8.2 \mathrm{rad} / \mathrm{s}$.

\subsubsection{Model (b)}

For the implicit analyses of this model the analytical rigid surface was considered to be fixed and a vertical concentrated force was applied at the tyre centre, while the latter was allowed to move freely in the vertical direction. Following that, the rigid analytical surface was replaced with a deformable soil layer, on which the tyre is rolling during the transient stage of the analysis. The displacement along $y$-axis and the rotations along the $x$ - and $z$-axes of the model at the rim of the tyre were held fixed during this final stage. It is noted that the way the amplitude of the various loads is applied in the model affects significantly the quality of the results. In particular, it was found that by applying a smooth step amplitude instead of its simple definition, lead to the elimination of numerical noise associated with the assumptions mentioned in Section 2.6. Ideally, the application of a ramp amplitude for a prolonged time duration would yield results of optimum accuracy; however, this case involves a computationally heavier model (greater 
number of elements) in terms of maintaining an acceptable aspect ratio of the elements since the dimensions of the road would increase.

\subsection{Various assumptions}

The rim of the tyre model is rigidly constrained to the motion of a reference point defined at its centre. Contact interaction is defined between the tyre and the underlying surface (be it an analytical rigid surface or the surface of a deformable part), in order to avoid interpenetration between the two surfaces and Coulomb friction is specified in the tangential direction of the tyre-terrain interface, with a friction coefficients of 1.0 for model (a) and 0.5 for model (b). The kinematic formulation was used in all the analyses, which, although computationally more intensive, provides increased accuracy in the results, especially when it used in conjunction with adaptive meshing techniques. Before imposing the vertical force load at the tyre centre or the road, initial contact is established to avoid spurious dynamic effects originating from the impact of the tyre on the rolling surface. Finally, in model (b), the deformable part representing the soil was considered to be homogeneous. For both models (a) and (b), lumped mass was added at the centre of the tyre, as well as rotary inertias in all degrees of freedom, in order to avoid numerical problems emerging from zero pivots during the explicit finite element analysis.

It has to be noted here that in each increment of ABAQUS/explicit, the acceleration is calculated by the multiplication of the inverse of the diagonal mass matrix with the difference between the imposed load and the internal forces, which does not ensure perfect equilibrium conditions in each time step. Apart from this, the central-difference operator used in ABAQUS/explicit is conditionally stable, and its stability limit depends on the highest eigenfrequency of the system. As a result, the acceleration calculated in this way may show spurious oscillations in certain cases, especially for impact loading conditions, an example of which will be presented in Section 4.2, and which, become smoother and eventually disappear as the acceleration is integrated according to the explicit central-difference integration rule. For example, to reduce the spurious oscillations in the acceleration response, the time increment size has to be reduced significantly in the part of the analysis after the bump impact.

\subsection{Mesh adaptivity}

To avoid high element distortion and consequent numerical errors and/or instabilities the adaptive meshing (ALE) option offered in ABAQUS/Explicit was utilised in the simulation. One remeshing sweep every ten increments was performed, where the calculation of the new mesh is based on the priority of improving the aspect ratio of the elements. It should be noted that these parameters affect the simulation time to a large extent. The simulation time of the models analysed in this study (model (b)) ranges from $16 \mathrm{~h}$ to $35 \mathrm{~h}$. The ALE was set only on the region of the model where the mesh was refined. Given that ALE cannot be implemented in a parallel processing mode, the size of the mesh was minimised, since otherwise high computational cost may occur. A mesh sensitivity study has been performed and the final mesh size was chosen such that the reduction of the element size in successive refinements gave an error of lower than $5 \%$. It should be noted that ALE works only with the contact pair formulation and not with general contact. 


\section{Footprint analysis results}

The mesh configuration which was used for the footprint analysis is shown in Figure 4(a). This includes a refinement near the contact area and is used to extract the results shown in Figure 5. In Figure 5(a), the vertical deflection vs. the vertical load is plotted for various values of the inflation pressure. It is evident that as the inflation pressure increases, the vertical deflection decreases, for all values of the vertical load considered. Moreover, as the vertical load increases, the vertical deflection increases. The differences between the vertical deflections for the various inflation pressures are more pronounced for increased values of the vertical load. In Figure 5(b), the contact area of the footprint is plotted vs. the vertical load, for the same values of the inflation pressures as in Figure 5(a). The contact area seems to have higher fluctuations as the vertical load changes. The results presented in Figure 5 correspond to frictionless contact between the tyre and the analytical surface.

Figure 4 Mesh configuration of the tyre used: (a) for the steady state transport analysis and (b) for the transient dynamic analysis in this study

(a)

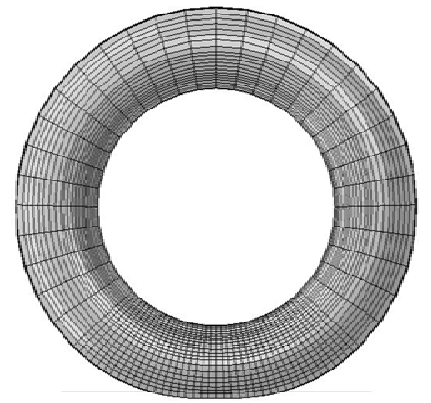

(b)

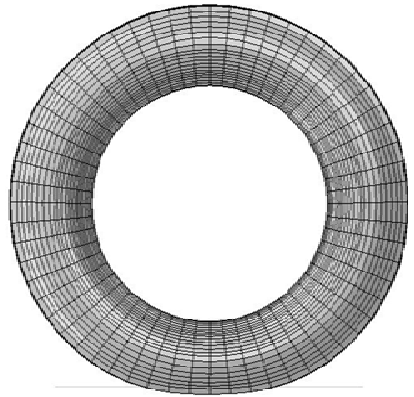

Figure 5 Results of footprint analysis for model in Figure 4(a): (a) vertical deflection vs. vertical load for various inflation pressures and (b) contact area vs. vertical load for various inflation pressures
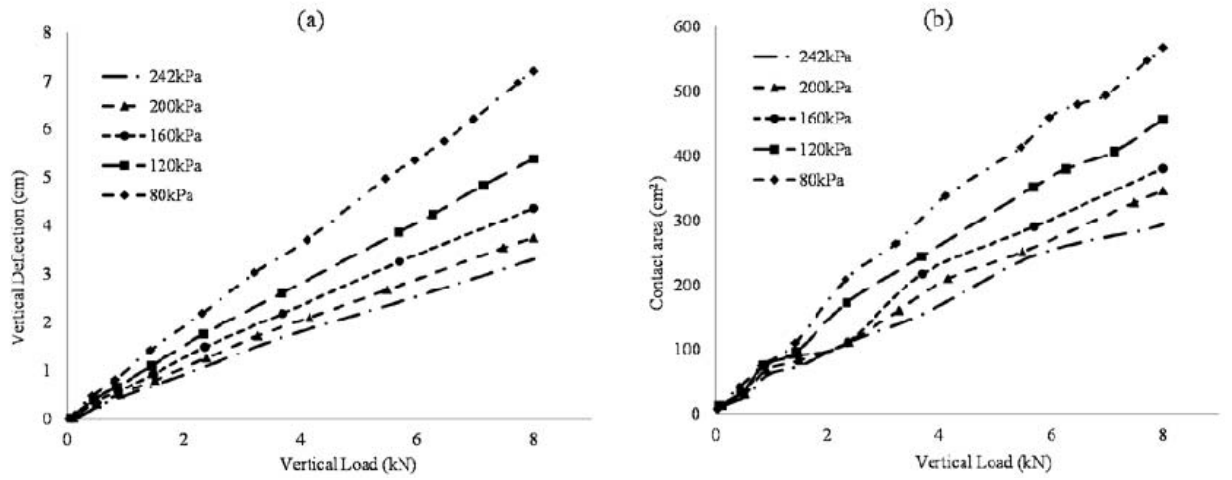

Another parameter examined is the effect of the rebar orientation of the two belt layers on the deflection of the tyre. The rebar orientation is defined as the angle between the axis of the rebar with respect to the local 1-direction. The three cases considered include belt 
layers with rebar orientation $\pm 18^{\circ}, \pm 20^{\circ}$ and $\pm 22^{\circ}$. The results are shown in Figure 6 , where the deflection of the tyre vs. the vertical load is plotted for various rebar orientations. It can be noted that by increasing the rebar orientation angle there is a decrease in the stiffness of the tyre since the vertical deflection increases.

Figure 6 Deflection vs. vertical load for various orientations of the rebar of the belt layers

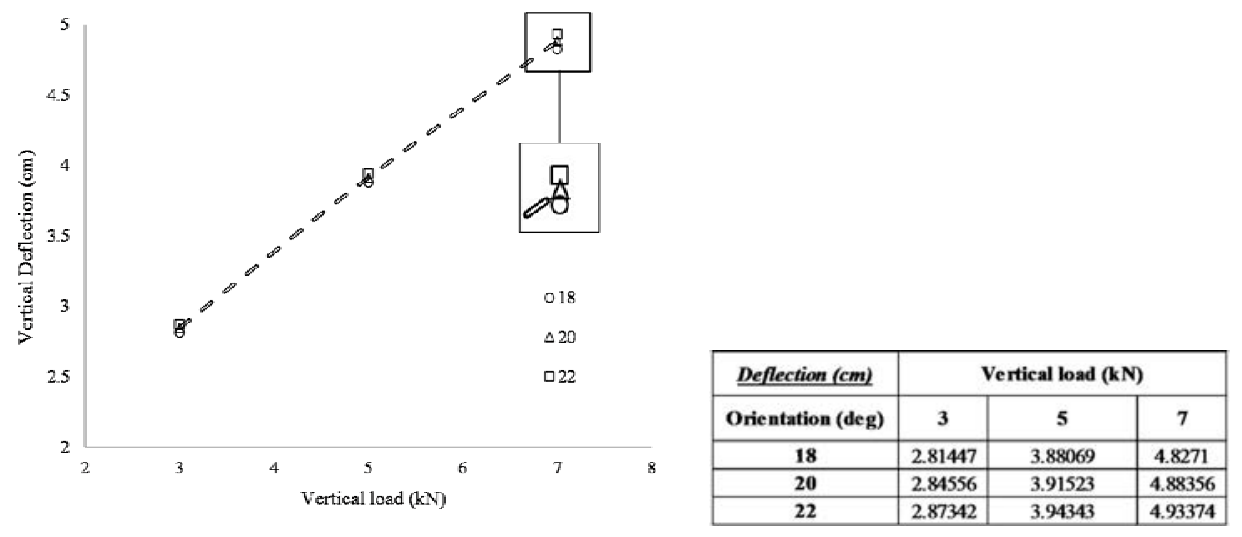

\section{Tyre rolling on rigid analytical surface}

\subsection{Steady-state transport (SST) analysis}

For a vertically loaded tyre rolling over a surface the combination of linear and angular velocity which results in free rolling conditions is not known in advance. The SST capability implemented in Abaqus can be considered as a mixed Lagrangian-Eulerian method, where the rotation of the tyre is described in a spatial or Eulerian manner, and the tyre deformation is described in a material or Lagrangian manner. This description of the steady-state rolling tyre with moving contact with the above formulation results in a spatially dependent simulation.

In Figure 7, results of the SST analysis are presented for various values of the vertical load, in terms of resistance force and torque with respect to the axis of revolution of the tyre. At the left area of each graph, braking conditions prevail, which lead to resistance forces opposite to the direction of travel and negative torque. After the point in which each curve intersects the horizontal axis and in the right area of each graph, traction conditions are being imposed at the tyre, which lead to negative resistance force and positive torque. At the extreme left and right ends of each graph, the friction between the tyre and the surface is predominant. In this regime, the resistance forces tend asymptotically to the corresponding sliding friction forces, whereas the torques tend asymptotically to the product of the friction forces with the radius of the deformed tyre. As a matter of course, the two asymptotic values of each quantity corresponding to the left asymptote and the right end are opposite in sign. The conditions in which the resistance force and the torque become zero (free rolling conditions) are different for 
the various values of the vertical load, although this difference is subtle. As the vertical load increases, the angular velocity corresponding to the free rolling conditions increases, for constant linear velocity, which in Figure 7 is assumed to be equal to $2.78 \mathrm{~m} / \mathrm{s}$.

Figure 7 Results of SST analysis for model in Figure 4(a): (a) rolling resistance force vs. angular velocity and (b) torque vs. angular velocity for various vertical loads

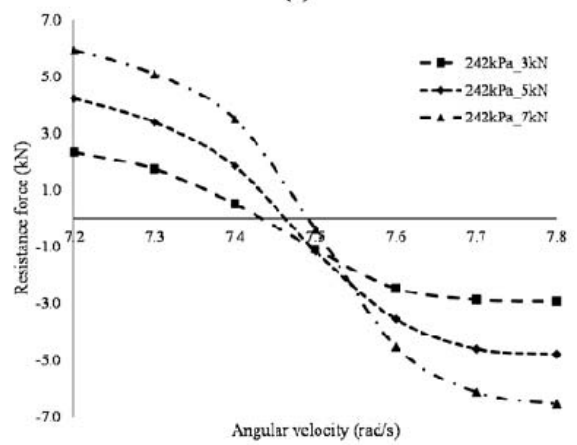

(b)

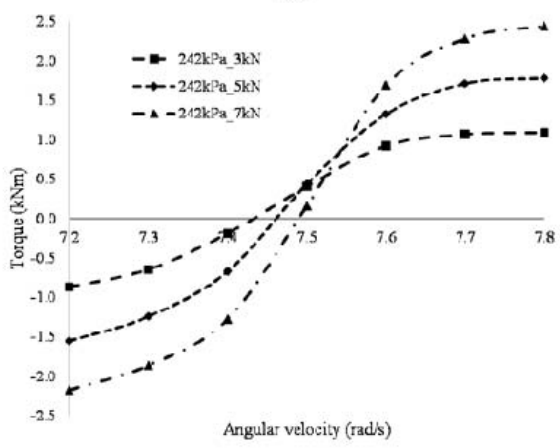

In Figure 8, the angular velocity is plotted against the linear velocity, for free rolling conditions of the tyre. The results presented in this figure are useful to identify the angular velocity which leads to free rolling conditions, for a given linear velocity, and they hold for the specific tyre considered in this study. It is obvious that there is a linear relation between the linear velocity and angular velocity in the graph of Figure 8 . This fact implies that there is a unique radius of the tyre which corresponds to free rolling conditions. In the subsequent transient analyses of the tyre rolling on an analytical rigid surface, combinations of linear and angular velocities were selected, which lie on the curve of Figure 8.

Figure 8 Results of SST analysis for model in Figure 4(a): identification of free rolling conditions

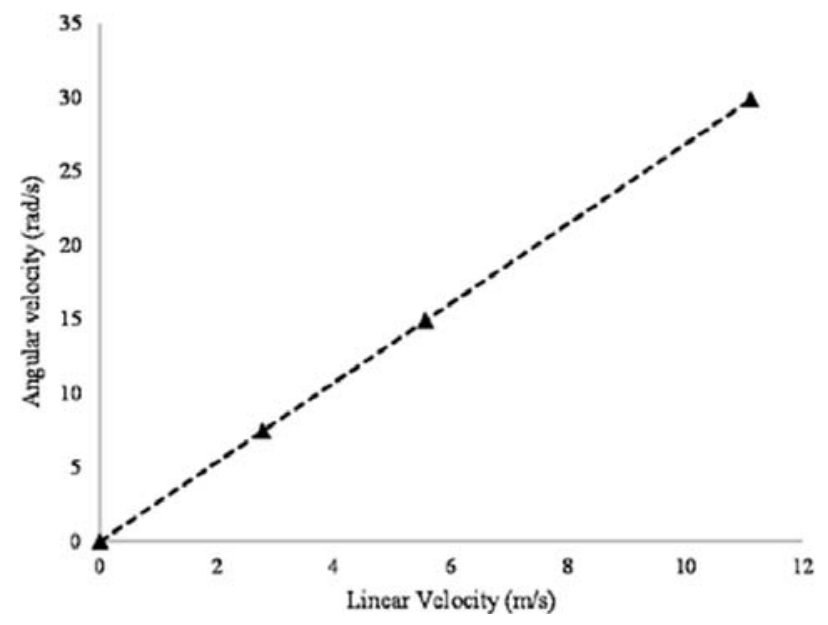




\subsection{Dynamic response due to speed bump impact}

It is well known that no road or terrain is free of obstacles. All rolling surfaces have irregularities of various sizes, which occupy larger or smaller portions of the surface. It is important that a tyre be designed against impacts originating from travelling over obstacles. In this study, various cases of vertical loads and rolling velocities are considered for a pneumatic tyre which, while rolling on a rigid surface free of irregularities in free rolling conditions, hits on a speed bump with specific configuration, as mentioned in the modelling section of this study. This analysis is dynamic transient and its results exhibit the effects of the dynamic response due to the load imposed by the bump (Figure 9). The values of the parameters for the various cases considered in this section are shown in Table 1.

Figure 9 Transient rolling process of a wheel impacting on a rigid bump

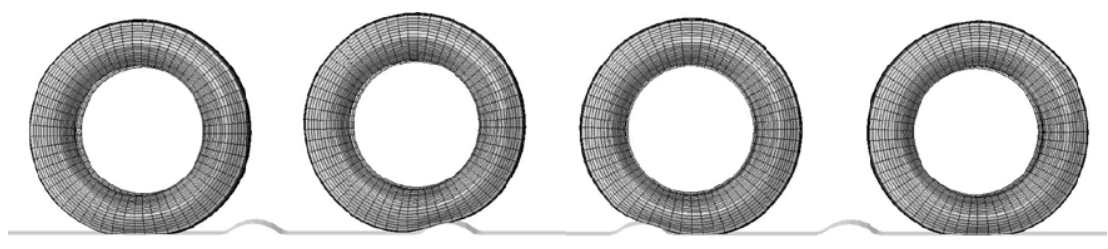

Table 1 Values of inflation pressure, vertical load and linear velocity considered for the cases analysed in Figures 10 and 11 of the current study

\begin{tabular}{lccc}
\hline Figure & Inflation pressure $(\mathrm{kPa})$ & Vertical load $(\mathrm{kN})$ & Linear velocity $(\mathrm{m} / \mathrm{s})$ \\
\hline $10(\mathrm{a})$ & 160 & 5 & 2.78 \\
& 200 & & \\
& 242 & 3 & 2.78 \\
$10(\mathrm{~b})$ & 242 & 5 & \\
& & 5 & 2.78 \\
$11(\mathrm{a}, \mathrm{b})$ & 200 & & 5.56 \\
\hline
\end{tabular}

In Figure 10, results of the dynamic response of the tyre due to the impact on the rigid bump are presented, in terms of the vertical displacement at its centre. In Figure 10(a), the effect of the inflation pressure on the vertical displacement is shown, for vertical load $5 \mathrm{kN}$ and linear velocity $2.78 \mathrm{~m} / \mathrm{s}$, whereas in Figure 10(b) the effect of vertical load applied at the centre of the tyre is shown for inflation pressure $242 \mathrm{kPa}$ and linear velocity $2.78 \mathrm{~m} / \mathrm{s}$. It has to be mentioned that the tyre configuration used for the tyre/bump impact analysis is shown in Figure 4(b), since uniformity along the tyre perimeter is required. It was ensured that the mesh refinement used for the tyre is as low as possible in order to give consistent results with the refined version and at the same time keep the computational cost in the explicit analysis as low as possible. It is apparent that the increase of the inflation pressure in Figure 10(a) reduces the oscillations, due to the change of the eigenvalues of the tyre. However it should be noted that the response of the tyre is highly dependent on the geometry of the bump; for instance a long and narrow 
bump will accelerate the tyre in the vertical direction to a different degree than a short bump. In loading cases such as the speed bump impact considered here, the free response of the system depends on the ratio between its eigenperiod and the duration of the bump impact; however, no monotonic dependence exists between this ratio and the maximum free dynamic response of the system, and this relation is rather complicated. It is apparent that in Figure 10(a) damping increases with decreasing inflation pressure. This conclusion is drawn by noting that the decrease between the consecutive peaks of the response is largest for $160 \mathrm{kPa}$ while for the highly inflated tyre $(242 \mathrm{kPa})$ it is much lower. In addition, in Figure 10(b), the effect of the vertical load on the dynamic response denotes that for increasing vertical load, the tyre is experiencing larger compression ratios, which results in a more stable condition for the tyre and therefore reduced vibration amplitude of the spindle.

Figure 10 Vertical displacement of the centre of the tyre during and after its impact with the bump: (a) effect of inflation pressure and (b) effect of vertical load

(a)

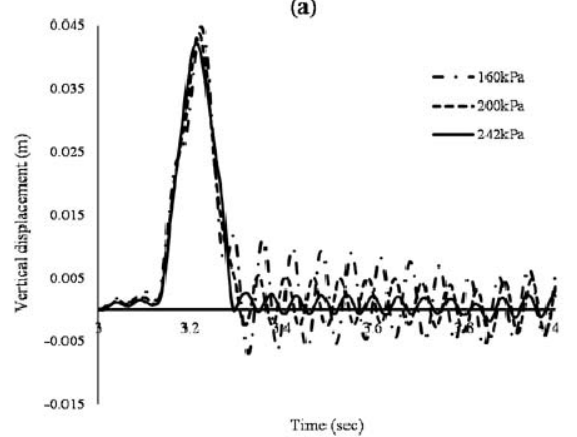

(b)

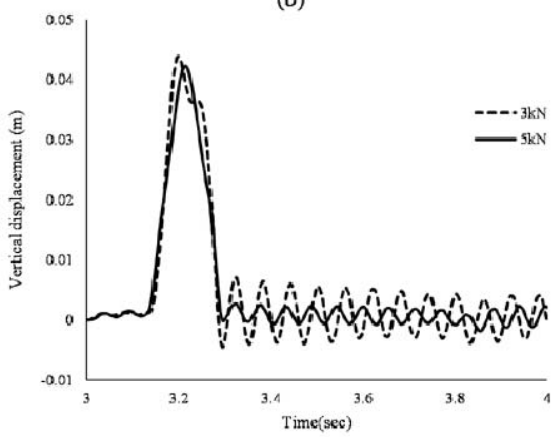

It has to be noted here that the ongoing oscillation of the tyre spindle after it passes the bump diminishes gradually due to the viscoelastic properties of the rubber, and eventually becomes zero, a condition which is not shown in Figure 10, as it is not reached for the time span of the analyses performed in this study. The amplitude of this oscillatory response is determined by the ratio of the time duration of the impact load to the eigenperiod of the most significant tyre eigenmode excited from the dynamic loading, in accordance to the basic theory of dynamics of single degree of freedom systems (Chopra, 2012).

In Figure 11, the effect of the free rolling velocity on the vertical dynamic response of the tyre spindle is depicted, for a tyre with vertical load equal to $5 \mathrm{kN}$ and inflation pressure $200 \mathrm{kPa}$. In Figure 11(a), the time history of the displacement at the centre of the tyre is shown, whereas in Figure 11(b) the time history of the acceleration at the centre of the tyre for the same case studies is presented. It is noted that for increased velocity the time duration of the bump impact decreases, which alters the ratio of the duration time to the eigenperiod of the tyre, a substantial factor which determines the displacements, velocities and accelerations in the vertical direction during and after impact loading. It is a matter of course that due to the complexity of the impact phenomenon (which depends on many factors, such as the bump geometry, for example), there is no universal 
trend regarding the aforementioned effects. In Figure 11(b), the respective accelerations for the same cases are shown. It is obvious that the acceleration response in the case of the higher velocity is much more pronounced, reaching a maximum value of $300 \mathrm{~m} / \mathrm{s}^{2}$, whereas the maximum value of the acceleration in the case of the lower velocity is roughly equal to $100 \mathrm{~m} / \mathrm{s}^{2}$.

Figure 11 Vertical response of the spindle due to rigid bump impact: (a) effect of free rolling velocities on displacement and (b) effect of free rolling velocities on acceleration, for a tyre with vertical load $5 \mathrm{kN}$ and inflation pressure $200 \mathrm{kPa}$

(a)

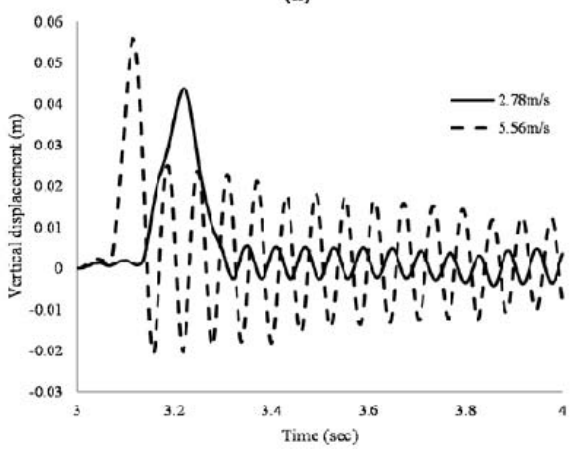

(b)

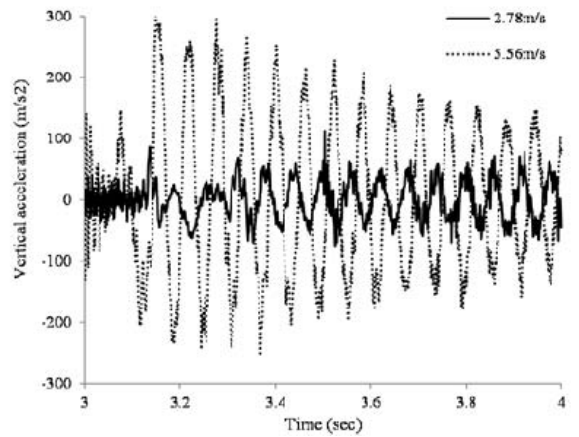

It is observed in Figure 11 that the time history of the vertical acceleration response is slightly corrupted with noise. The sources of this noise are primarily the nature of the explicit solver procedure, as outlined in Section 2.6, as well as the contact formulation at the tyre-rigid surface interface. Contact-induced noise can occur if a surface of a much denser body is weighted as a slave surface, as was done in the numerical procedure followed to obtain the presented results. The solution noise can be reduced in terms of reaching a more stable solution regarding vertical displacement and acceleration of the spindle after the impact with the specification of contact damping in ABAQUS/explicit, use of the penalty contact formulation and/or reduction of the time increment of the analysis after the impact as suggested by Cho et al. (2005). However, contact damping is not available for hard kinematic contact which was nevertheless preferred here in terms of maintaining a consistency among models (a) and (b) and the time increment was not altered in order to maintain an affordable computational cost for the analyses performed herein, since the main objective of this section was the dynamic response of the tyre due to inflation pressure, velocity and vertical load changes at the moment of impact.

The oscillations of the spindle during impact observed may be caused by

- the assumption about zero strain rate for the calculation of the Mooney-Rivlin parameters during the optimisation process (Bekakos, 2016a) and/or

- $\quad$ induced numerical noise by the Abaqus/explicit solver which was used for the dynamic analyses.

It should be noted that this kind of oscillations (noise) is observed at the literature (e.g., Palanivelu et al., 2015). 


\section{Tyre rolling on soft soil}

The configuration used for the analysis of this section is shown in Figure 3 with the tyre configuration presented in Figure 4(b). The values of the parameters for the various cases considered in this section are shown in Table 2.

Table 2 Values of inflation pressure, vertical load, linear velocity, angular velocity, cohesion and friction angle considered for the cases analysed in Figures 12-15 of the current study

\begin{tabular}{|c|c|c|c|c|c|c|}
\hline Figure & $\begin{array}{c}\text { Inflation } \\
\text { pressure }(\mathrm{kPa})\end{array}$ & $\begin{array}{c}\text { Vertical load } \\
(-)\end{array}$ & $\begin{array}{l}\text { Linear velocity } \\
(\mathrm{m} / \mathrm{s})\end{array}$ & $\begin{array}{c}\text { Angular velocity } \\
(\mathrm{rad} / \mathrm{s})\end{array}$ & Cohesion-) & $\begin{array}{l}\text { Friction } \\
\text { angle }\left({ }^{\circ}\right)\end{array}$ \\
\hline \multirow[t]{2}{*}{ 12(a) } & 242 & $1.2 \gamma \mathrm{gbd}^{2}$ & 1.39 & - & $1.25 \gamma \mathrm{gd}$ & 0 \\
\hline & & & 2.78 & & & \\
\hline \multirow[t]{2}{*}{$12(b)$} & 242 & $1.2 \gamma \mathrm{gbd}^{2}$ & 2.78 & - & & \\
\hline & & $2 \gamma \mathrm{gbd}^{2}$ & & & & \\
\hline \multirow[t]{2}{*}{13} & 200 & $1.2 \gamma \mathrm{gbd}^{2}$ & 1.39 & - & & \\
\hline & 242 & & & & & \\
\hline \multirow[t]{4}{*}{ 14(a) } & 120 & $1.2 \gamma \mathrm{gbd}^{2}$ & - & 7.46 & & \\
\hline & 160 & & & & & \\
\hline & 200 & & & & & \\
\hline & 242 & & & & & \\
\hline \multirow[t]{2}{*}{$14(b)$} & 120 & $1.2 \gamma \mathrm{gbd}^{2}$ & - & 7.46 & & \\
\hline & 242 & & & & & \\
\hline \multirow[t]{2}{*}{15} & 242 & $0.8 \gamma \mathrm{gbd}^{2}$ & - & 7.46 & & \\
\hline & & $1.2 \gamma \mathrm{gbd}^{2}$ & & & & \\
\hline
\end{tabular}

\subsection{Towed wheel conditions}

Towed wheels considered in this study are loaded only with horizontal linear velocity and vertical force, imposed on the centre of the rim. Their rotation occurs due to the friction between the tyre and the rolling surface. However, yielding of the soil material may cause the immobilisation of the wheel, depending on the combination of the vertical load, the linear velocity and the inflation pressure. On the basis of these, a parametric study was conducted in which the effect of the aforementioned parameters was taken into account for the calculation of the dynamic interaction between towed wheels and the supporting soil. Consideration of this dynamic interaction can lead to efficient design of the wheel, in order to minimise the response, and other parameters, such as fuel consumption.

In Figure 12, results of the angular velocity of the towed wheel are shown, vs. its horizontal displacement at the direction of travel. The inflation pressure of the tyre is considered to be equal to $242 \mathrm{kPa}$. In Figure $12(\mathrm{a})$, the effect of linear velocity is demonstrated for wheel with vertical load equal to $1.2 \gamma \mathrm{gbd}^{2}$. Initially, the wheel rolls over the rigid domain of the rolling surface. After travelling a distance of $0.4 \mathrm{~m}$, it enters the deformable region of the soil, and the angular velocity gradually decreases. This happens due to the fact that as the soil yields due to the loading of the wheel, the stress distributions under the tyre become lower due to the soil strength limitations; therefore 
the friction force is reduced at the tyre-soil interface. As a result, due to the decreased friction force, the angular velocity decreases gradually, until it becomes zero at a certain point, meaning that the wheel exhibits pure translational motion without rotation. The angular velocity further decreases, becoming negative for a very small travelling distance, after which it becomes constantly zero. Comparing the two curves for different velocities and observing that for the higher velocity the peak negative angular velocity increases, this fact can be explained by taking into account that the accumulation of the soil in the front of the of the wheel leads to opposite friction forces, which cause the rotation of the wheel with negative angular velocity. This motion is further reversed due to the rotational inertia that has been developed by the wheel. The tyre with the higher velocity will exhibit exactly the same pattern of motion for a longer travelling distance, but this has not been plotted explicitly due to space reasons. In Figure 12(b), the angular velocity vs. the horizontal displacement of the wheel is illustrated for a wheel with the same inflation pressure and translational velocity but two different vertical loads applied at the spindle. It is observed that the wheel with vertical load $1.2 \gamma \mathrm{gbd}^{2}$ experiences a higher friction force, which develops due to the decreased yielding response of the underlying soil. Apart from this, the decreasing slope of the curve is lower than that of the curve corresponding to vertical load $2 \gamma \mathrm{gbd}^{2}$, till the wheel travels at a distance of $1 \mathrm{~m}$. After this point, as the increased vertical load incurs increased compaction of the underlying soil, the distance needed for the immobilisation of the wheel with vertical load $2 \gamma \mathrm{gbd}^{2}$ is higher than that for vertical load $1.2 \gamma \mathrm{gbd}^{2}$. To avoid numerical noise associated with the assumptions mentioned in Section 2.6, filtering (of the butterworth type) was performed during the post-processing of the results.

Figure 12 Angular velocity of the towed wheel considered in this study rolling on soft soil $(c=1.25 \gamma \mathrm{gd}, \varphi=0, \psi=0)$ : (a) effect of linear velocity and (b) effect of vertical load

(a)

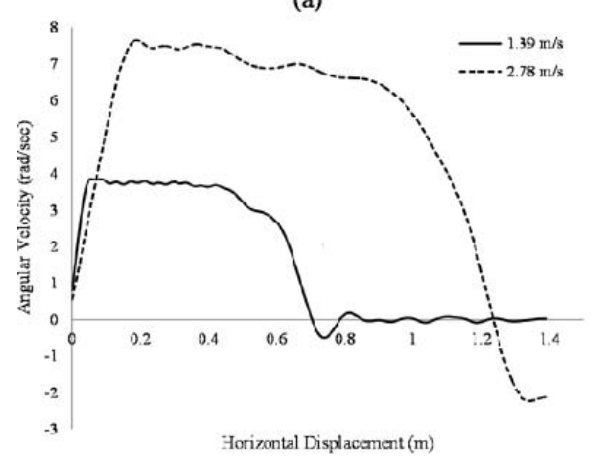

(b)

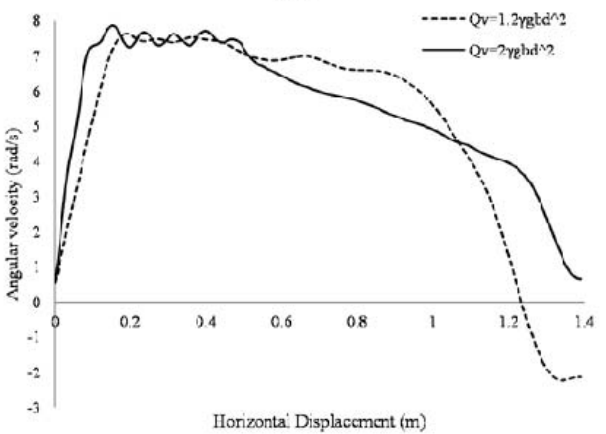

In Figure 13, a wheel with a vertical load of $1.2 \gamma \mathrm{gbd}^{2}$ and translational velocity of $1.39 \mathrm{~m} / \mathrm{s}$ for two different inflation pressures is investigated. Its angular velocity is plotted in Figure 13(a), whereas in Figure 13(b) the deformed configuration of the tyre and the soil is shown. A clear trend observed in Figure 13(a) is the longer distance that is travelled by the wheel with decreased inflation pressure. This occurs due to the fact that for lower inflation pressures (considering the same amount of vertical load) the contact area at the tyre-soil interface increases, which results in lower pressures transmitted into the soil, which in turn leads to slower yielding response and consequently longer travelling distance. In Figure 13(b), it is apparent that the mesh adaptivity technique has 
successfully captured the soil accumulation in the region surrounding the wheel footprint causing the bulldozing effect. Although the phenomenon of soil accumulation (observed both numerically and experimentally by Hambleton and Drescher (2008) and Wong and Reece (1967a, 1967b), respectively) does not validate any specific numerical results, it is a clear indication of the realistic dynamic tyre-terrain response and has been observed in all models considered in the current study.

Figure 13 (a) Angular velocity of the towed wheel on soft soil $(c=1.25 \gamma \mathrm{gd}, \varphi=0, \psi=0)$ vs. horizontal travelling distance for various inflation pressures and (b) deformed geometry of the tyre-soil system
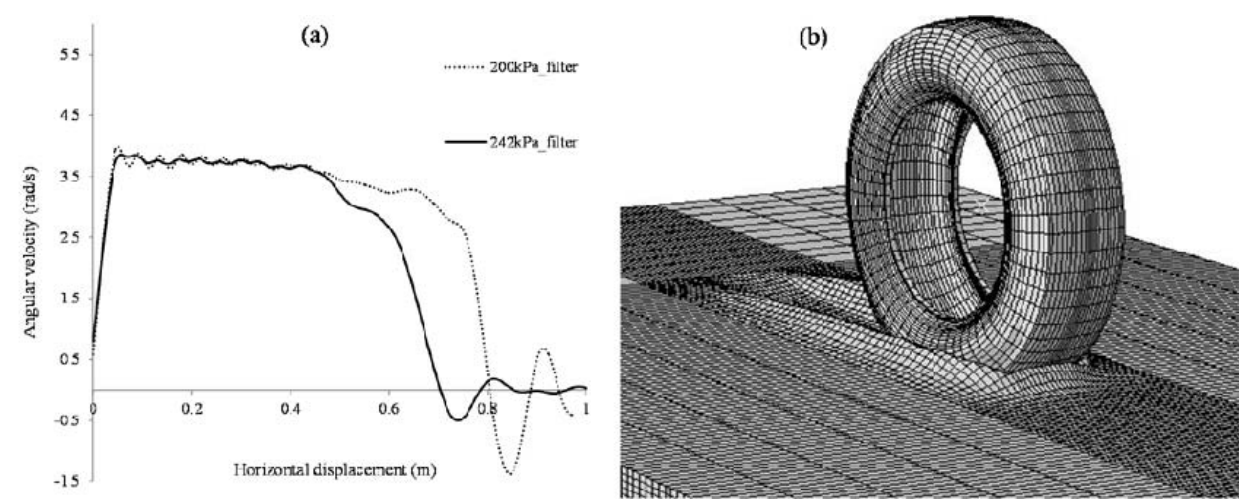

\subsection{Driven wheel conditions}

A more common representation of the wheels used for off road vehicles is the one of the driven wheel, where an angular velocity is imposed at the spindle of the wheel through the shaft axle and the wheel moves due to the friction that develops at the interface between the tyre and the rolling surface. Although the inflation pressure should be relatively high for on-road vehicles in order to reduce various parameters such as the rolling resistance, in off-road vehicles a balance should maintained between the sinkage of the wheel into the soil and the resistive forces being developed by the tyre-terrain interaction.

In Figure 14(a), the dimensionless sinkage of the driven wheel with $\omega=7.46 \mathrm{rad} / \mathrm{s}$ and vertical load $1.2 \gamma \mathrm{gbd}^{2}$, for four distinct values of inflation pressure is plotted against travelling time. The sinkage $(s)$ is non-dimensionalised by dividing it with the sinkage of the wheel resting on a rigid surface $\left(s_{0}\right)$, which occurs purely due to the tyre deformation. It appears that as the inflation pressure increases, the dimensionless sinkage increases also, and this trend is more pronounced after the wheel fully enters the soft soil. This is a direct consequence of the fact that by reducing the inflation pressure, the contact area of the tyre footprint increases, and therefore lower pressures at the tyre-soil interface. It is observed that the sinkage of the wheel into the soil increases until it reaches a peak value, which occurs approximately at $0.25 \mathrm{~s}$ (1.25 $\mathrm{s}$ at the horizontal axis). After this peak value, the sinkage decreases and oscillates around a constant value, which is called the quasi-steady-state sinkage. Quasi-steady-state response is presented for a simulation time of $0.5 \mathrm{~s}$. It has to be noted that the time period required for the wheel to attain its steady-state response is a function of its size, inflation pressure, vertical load and the soil properties. Furthermore, similar trends for wheels interacting with deformable terrains 
have been observed in the literature both experimentally (Hambleton and Drescher, 2009) and numerically (Bekakos et al., 2015). In these studies, rigid wheels with various widths have been considered, whereas in the current study the variation of width is indirectly addressed through the variation of the inflation pressure; the effects of the two parameters are similar, since by decreasing the inflation pressure the contact area (and consequently the tyre width) increases. Therefore, the qualitative similarity between the two different trends shows that the corresponding effects have been adequately captured in the models.

Figure 14 (a) Dimensionless sinkage and (b) linear velocity of a wheel on soft soil ( $c=1.25 \gamma \mathrm{gd}$, $\varphi=0, \psi=0)$ with $\omega=7.46 \mathrm{rad} / \mathrm{s}$ and $Q_{v}=1.2 \gamma \mathrm{gbd}^{2}$ for a wide range of inflation pressures

(a)

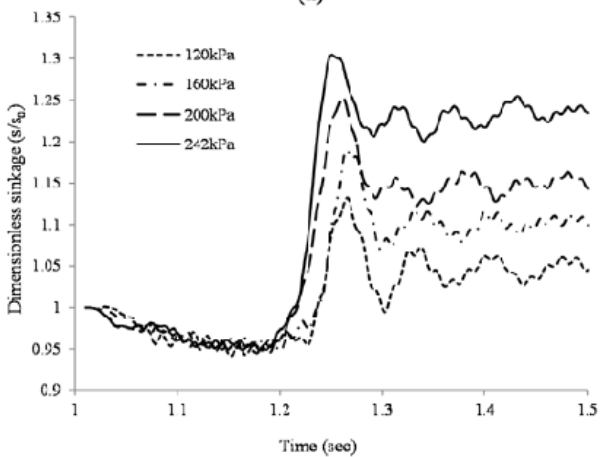

(b)

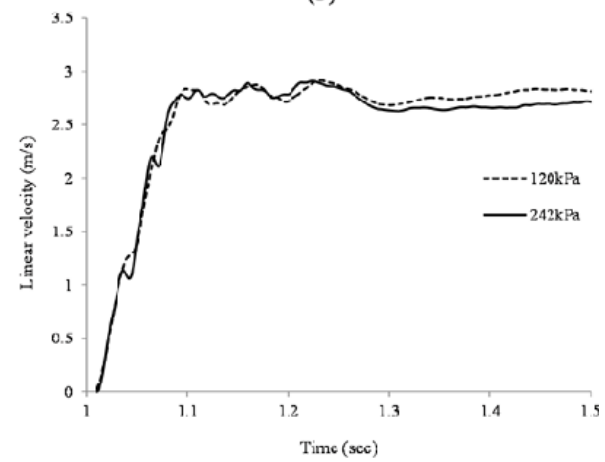

In Figure 14(b), it seems that in steady-state conditions the tyre with the higher inflation pressure travels with a lower velocity, which results from the higher dimensionless sinkage and narrower footprint area compared to the tyre with the lower inflation pressure, in which case a smaller dimensionless sinkage and wider footprint area occur. For driven wheels, the linear velocity is primarily determined by two main effects: the rolling radius and the vertical displacement of the wheel into the soil. Regarding the rolling radius, its value results from the combined effect of the inflation pressure and the vertical load. For instance, for a given inflation pressure and two different vertical loads, two different rolling radii will result. Regarding the sinkage of the wheel, it depends on the pressure distribution transmitted from the footprint to the soil; this distribution is a function of the combined effect of the inflation pressure, the vertical load and the soil properties. The outcome of this interdependence is that there are two conflicting trends relating the inflation pressure and/or the vertical load, and the linear velocity.

In Figure 15, the dimensionless sinkage of the wheel with angular velocity equal to $7.46 \mathrm{rad} / \mathrm{s}$ and inflation pressure equal to $242 \mathrm{kPa}$ is plotted vs. time. For the time duration from $1 \mathrm{~s}$ to $1.2 \mathrm{~s}$ the wheel is rolling over the rigid surface, whereas for the remaining time duration of the analysis the wheel is rolling on soft soil. It is shown that by increasing the vertical load the dimensionless sinkage increases. Moreover, the undulations during the quasi-steady-state response are more pronounced for increased vertical load. It is noted that the peak in the dimensionless sinkage which exists at the time instant of roughly $1.25 \mathrm{~s}$ (as noted at the axis) occurs due to the steep variation of the rolling surface as the wheel enters the soft soil from the rigid surface. Due to this discontinuity, an oscillation begins, which lasts all over the steady-state response, eventually attained by the tyre-soil system. For larger values of vertical load, the 
quasi-steady-state sinkage increases as expected. However, the applied vertical force cannot exceed certain limits, at which the underlying soil comes to a state of failure. These limits are determined by the bearing capacity of the soil.

Figure 15 Dimensionless sinkage of a wheel on soft soil $(c=1.25 \gamma \mathrm{gd}, \varphi=0, \psi=0)$ with $\omega=7.46 \mathrm{rad} / \mathrm{s}$ and inflation pressure $242 \mathrm{kPa}$ for two values of the vertical load

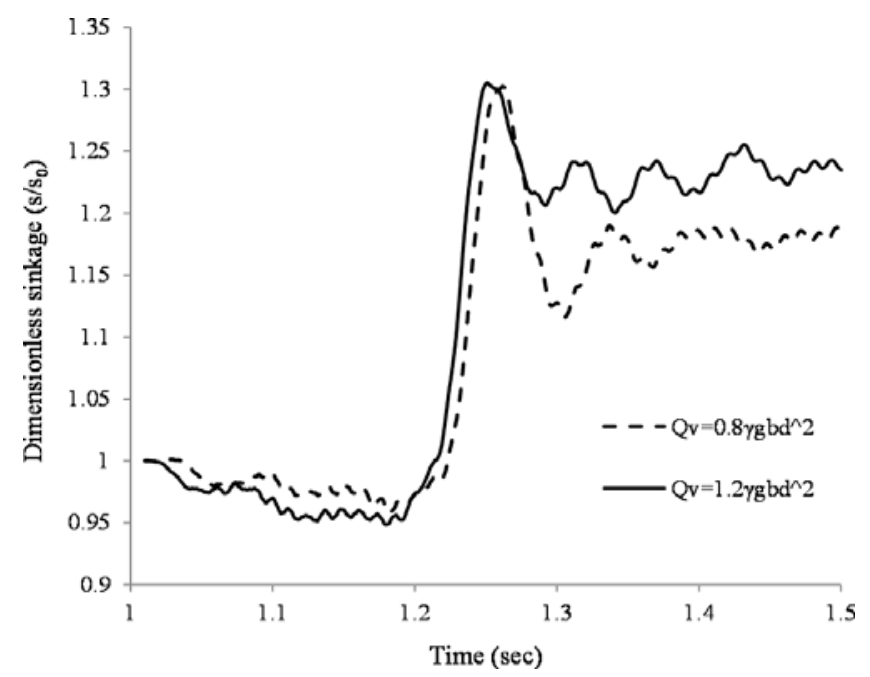

\section{Conclusions}

The dynamic tyre-terrain interaction between a deformable pneumatic tyre (P235/75R17) and a rigid or deformable surface was studied using the finite element method with a realistic and detailed numerical model involving advanced capabilities.

Initially the static footprint solution of the tyre loaded against a rigid analytical surface representing a stiff pavement and it was verified that the tyre exhibits realistic behaviour.

The free rolling conditions were then obtained for the tyre rolling on a rigid surface using a SST analysis which involves mixed Eulerian-Lagrangian descriptions and it was found that its results were reliable.

Following this, the impact of the tyre in free rolling conditions on an obstacle (more specifically a bump) was simulated and it was shown that that the dynamic response is a function mainly of the bump geometry and the tyre eigenproperties which signifies that the overall problem can be reduced to a fundamental impulse excitation problem.

In addition, the tyre was considered to be rolling on a soft soil under towed conditions, and it was found that the reduction of the inflation pressure allowed the wheel to travel in the deformable soil prior to its immobilisation for larger distance compared to the highly inflated tyre. In addition to that, the vertical load and linear velocity effects on the overall behaviour of the wheel was examined.

Moreover, the same tyre and soil as above were considered under driving conditions and it was found that contrary to the on-road tyres, reduction of the inflation pressure yields several benefits for the off-road tyres. More specifically by decreasing the inflation 
pressure the contact area at the tyre-terrain interface is increasing which results in smaller vertical displacement of the wheel into the soil. Furthermore, it should be noted that the behaviour of the rolling wheel into the soil results from the combined effect of the rolling radius and its vertical displacement into the soil. Both of the aforementioned factors are highly dependent on inflation pressure and vertical load.

The complex nature of the tyre-terrain dynamic interaction is apparent from the results of the simulations performed in this study, in which the main focus is set on the modelling techniques involved in the study of the static and/or dynamic response of rolling wheels on rigid or deformable terrain. Although the trends in the tyre response are in accordance with analogous results from the literature, the need remains for validating them against experimental data. Hence, future work will contain the setup of an experimental test rig capable of measuring driven and towed wheels' behaviour on deformable terrain.

\section{References}

Bekakos, C.A., Papazafeiropoulos, G., O’Boy, D.J. and Prins, J. (2015) 'Dynamic response of rigid wheels on deformable terrains', Proc.13th ISTVS European Conf., Rome, pp.588-600.

Bekakos, C.A., Papazafeiropoulos, G., O’Boy, D.J. and Prins, J. (2016a) 'Development of accurate pneumatic tyre finite element models based on an optimization procedure', ECCOMAS Congress 2016, VII European Congress on Computational Methods in Applied Sciences and Engineering, Greece. AUTHOR PLEASE SUPPLY PAGE RANGE.

Bekakos, C.A., Papazafeiropoulos, G., O’Boy, D.J. and Prins, J. (2016b) 'Pneumatic tyres interacting with deformable terrains', 13th International Conference on Motion and Vibration Control, 3-6 July, Southampton. AUTHOR PLEASE SUPPLY PAGE RANGE.

Bolarinwa, E. and Olatunbosun, O. (2015) On Finite Element Tyre Modal Analysis, SAE Technical Paper 2015-01-1518.

Chiroux, R.C., Foster Jr., W.A., Johnson, C.E., Shoop, S.A. and Raper, R.L. (2005) 'Threedimensional finite element analysis of soil interaction with a rigid wheel', Applied Mathematics and Computation, Vol. 162, pp.707-722.

Cho, J.R., Kim, K.W., Jeon, D.H. and Yoo, W.S. (2005) 'Transient dynamic response analysis of 3-D patterned tire rolling over cleat', European Journal of Mechanics A/Solids, Vol. 24, pp.519-531.

Chopra, A.K. (2012) Dynamics of Structures, theory and Applications to Earthquake Engineering, 4th ed., Prentice-Hall. AUTHOR PLEASE SUPPLY LOCATION.

Dorfi, H.R., Wheeler, R.L. and Keum, B.B. (2005) Vibration Modes of Radial Tires: Application to Non-rolling and Rolling Events, SAE 2005 Noise and Vibration Conference and Exhibition, Traverse City, Michigan.

Drucker, D.C. and Prager, W. (1952) 'Soil mechanics and plastic analysis or limit design', Quarterly of Applied Mathematics, Vol. 10, pp.157-165.

Fervers, C. (2004) 'Improved FEM simulation model for tire-soil interaction', Journal of Terramechanics, Vol. 41, Nos. 2-3, pp.87-100.

Ghoreishy, M.H.R. (2006) 'Steady state rolling analysis of a radial tyre: comparison with experimental results', Proc. IMechE, Vol. 220, Part D: J. Automobile Engineering, pp.713-721. AUTHOR PLEASE SUPPLY LOCATION.

Hambleton, J.P. and Drescher, A. (2008) 'Modeling wheel-induced rutting in soils: Indentation', Journal of Terramechanics, Vol. 45, No. 6, pp.201-211.

Hambleton, J.P. and Drescher, A. (2009) 'Modeling wheel-induced rutting in soils: rolling', Journal of Terramechanics, Vol. 46, No. 2, pp.35-47. 
Kamoulakos, A. and Kao, B.G. (1998) 'Transient dynamics of a tire rolling over small obstacles - a finite element approach with pam-shock', Tire Science and Technology, TSTCA, Vol. 26, No. 2, pp.84-108.

Kölsch, C. (2000) 'Vertical vehicle dynamics on soft ground-investigations with FEM', FISITA World Automotive Congress, pp.1-8. AUTHOR PLEASE SUPPLY LOCATION.

Lee, J.H. (2011) 'Finite element modeling of interfacial forces and contact stresses of pneumatic tire on fresh snow for combined longitudinal and lateral slips', Journal of Terramechanics, Vol. 48, pp.171-197.

Palanivelu, S., Rao, N.K.V. and Ramarathnam, K.K. (2015) 'Determination of rolling tyre modal parameters using finite element techniques and operational modal analysis', Mechanical Systems and Signal Processing, Vols. 64-65, pp.385-402.

Shoop, S.A. (2001) Finite Element Modeling of Tire-Terrain Interaction, University of Michigan, Report number: ERDC/CRREL TR-01-16.

SAE (2008) Vehicle Dynamics Terminology, Vehicle Dynamics Standards Committee, SAE International (J670_200801).

Wei, C. and Olatunbosun, O.A. (2014) 'Transient dynamic behaviour of finite element tire traversing obstacles with different heights', Journal of Terramechanics, Vol. 56, pp.1-16.

Wheeler, R.L., Dorfi, H.R. and Keum, B.B. (2005) 'Vibration modes of radial tires: measurement, prediction, and categorization under different boundary and operating conditions', SAE Noise and Vibration Conference and Exhibition, Traverse City, Michigan.

Wong, J.Y. and Reece, A. (1967a) 'Prediction of rigid wheel performance based on analysis of soil-wheel stresses, part I: Performance of driven rigid wheels', Journal of Terramechanics, Vol. 4, pp.81-98.

Wong, J.Y. and Reece, A. (1967b) 'Prediction of rigid wheel performance based on analysis of soil-wheel stresses, part II: Performance of towed rigid wheels', Journal of Terramechanics, Vol. 4, pp.7-25.

\section{Nomenclature}

\begin{tabular}{llr}
\hline$b$ & Wheel width or the smaller dimension of the wheel/terrain & {$[\mathrm{m}]$} \\
$c$ & contact patch & {$[\mathrm{Pa}]$} \\
$C_{01}$ & Soil cohesion (Mohr-Coulomb) & {$[\mathrm{Pa}]$} \\
$C_{10}$ & Mooney-Rivlin material parameter & {$[\mathrm{Pa}]$} \\
$D_{1}$ & Mooney-Rivlin material parameter & {$[\mathrm{Pa}]$} \\
$d$ & Mooney-Rivlin material parameter & {$[\mathrm{m}]$} \\
$d_{D P}$ & Tyre diameter & {$[\mathrm{Pa}]$} \\
$E$ & Cohesion (Drucker-Prager) & {$[\mathrm{Pa}]$} \\
$F_{D P}$ & Modulus of elasticity & {$[\mathrm{Pa}]$} \\
$g$ & Failure surface of DP model & {$\left[\mathrm{m} / \mathrm{s}^{2}\right]$} \\
$\bar{g}_{l}^{P}$ & Gravity constant & {$[-]$} \\
$\bar{I}_{l}$ & Shear relaxation modulus & {$[-]$} \\
$J^{e l}$ & First deviatoric strain invariant & {$[-]$} \\
$\bar{k}_{l}^{P}$ & Elastic volume ratio & Bulk relaxation modulus \\
$Q_{v}$ & Vertical load on wheel centre & {$[-]$} \\
\hline
\end{tabular}


Finite element modelling of a pneumatic tyre

\begin{tabular}{llc}
\hline$s$ & Depth of sinkage & {$[\mathrm{m}]$} \\
$s_{0}$ & Depth of sinkage due to tyre deflection & {$[\mathrm{m}]$} \\
$U$ & Strain energy per unit of reference volume & {$[\mathrm{Pa}]$} \\
$\gamma$ & Soil density & {$\left[\mathrm{kg} / \mathrm{m}^{3}\right]$} \\
$\sigma_{i}$ & Principal stress $(i=1,2,3)$ & {$[\mathrm{Pa}]$} \\
$\tau_{1}$ & Relaxation time & {$[\mathrm{sec}]$} \\
$\varphi$ & Friction angle (Drucker-Prager) & {$[\mathrm{deg}]$} \\
$\psi$ & Soil dilation angle & {$[\mathrm{deg}]$} \\
$\omega$ & Angular velocity of the wheel & {$[\mathrm{rad} / \mathrm{s}]$} \\
\hline
\end{tabular}

